\title{
Dust monitoring in Alibag using Ficus hispida $\mathrm{L}$
}

\begin{abstract}
Technology is an expensive method for monitoring any pollution in the atmosphere. In this work Ficus hispida a commonly growing weed in the coastal region of Alibag is used to monitor dust at various locations in the fast developing region. Ten sites were selected and foliar dust was monitored throughout the dry season of 2017. The dust fall showed seasonal variations at different sites and co- related well with local conditions prevalent at the site. The work throws light on the levels of dust pollution in the region and that Ficus hispida L. can effectively be used to monitor dust. The plant species has exceptionally rough surface with large leaves, which proves as effective dust capturer.
\end{abstract}

Keywords: monitoring dust, local biodiversity, Fisucs hispida, cheap effective method
Volume 2 Issue 6 - 2018

\author{
Nitesh Joshi,Vishakha Vaidya \\ Department of Botany, Rizvi College of Arts, Science and \\ Commerce, India
}

\begin{abstract}
Correspondence: Nitesh Joshi, Department of Botany, Rizvi College of Arts, Science and Commerce, Bandra, Mumbai, India, Email neteshcjoshi@gmail.com
\end{abstract}

Received: October 15, 2018 | Published: November 16, 2018

\section{Introduction}

Raigad district is a part of west coast of Arabian Sea. It has approximately $240 \mathrm{~km}$. coast in West of the Indian peninsular region. The district is rich in natural resources, and is geographically divided into sea coast, central belt and hilly Sahyadri ranges.

There are about 915 industries in Raigad region. Out of which 336 falls under RED category, 202 falls under ORANGE and remaining in GREEN category according to the pollution control boards.

Alibag is located about $120 \mathrm{~km}$ south of Mumbai at $18^{\circ} 38^{\prime} 29^{\prime \prime} \mathrm{N}$ $72^{\circ} 52^{\prime} 20^{\prime \prime}$ E. tourism is the mainstay of town's economy since the late 1990s. The town and municipality have seen development of industrial sites. RCF was the first industrial unit set up near Alibag at Thal. Other companies include JSW Steel at Dolvi, JSW Steel at Salav, Gas Authority of India Limited at Usar (GAIL), Marine Frontiers Boatyards located at Dharamtar.

Environmental pollution is an unwanted side effect of accelerated pace of industrialization during the past century. However industrialization cannot be stopped at this stage of our development. Since it has become indispensible for providing basic necessities of life. Vegetation is the best possible sink for atmospheric pollutants Plants also have been used to monitor dust. ${ }^{1}$ Leaves of plants have been regarded as bio filters as they absorb large quantities of particles from the environment. ${ }^{2,3}$

Table I Description of sites

\begin{tabular}{lll}
\hline S. no & Name of the site & Site description \\
\hline I & Anand nagar & Residential area with moderate traffic. \\
2 & Revas Road & Very heavy traffic \\
3 & Rautwadi Road & Heavy traffic \\
4 & Versoli Road & Moderate traffic \\
5 & Revdanda Bypass Road & Heavy vehicular traffic consisting of all types of vehicles. \\
6 & Gondhalpada road & Near residential area so less traffic. \\
7 & Pimpalbhat Road & Heavy continuous traffic. \\
8 & Khandala Road & Moderate traffic with heavy vehicles \\
9 & Chendhre bypass Road & Connecting road to highway, less traffic. \\
I0 & Karle Khind Road & Heavy traffic with all types of vehicles. \\
\hline
\end{tabular}

Plants intercepts tons of dust on busy highways and dust is never constant in the atmosphere. It keeps changing with respect to variations in place, time, season, climate, etc. Wind speed, air temperature, inversions, clouds cover all influence particle movements. ${ }^{4}$ The current work aims at understanding the dust holding capacity a roadside plants in Alibag. Alibag is the most favorite travel destination for people near Mumbai and Pune.

\section{Material and methods}

\section{Survey of Roadside Vegetation}

A survey of plants growing along roadsides and dividers was carried out in Alibag. Ficus hispida L. is a common weed frequently occurring in the region of Alibag. It has extremely rough surface. 10 dustiest sites on highways and heavy traffic areas were selected. The study was carried out in dry season i.e. from January 2017to May 2017. Leaves from this plant were selected from 10 sites and dust fall estimated.

\section{Estimation of dust fall}

Ten dustiest sites were selected. Few leaves of Ficus hispida L. were washed at the site and marked. At the $7^{\text {th }}$ day the leaves were washed and dust was estimated on the foliar surface. ${ }^{5}$ The leaves were washed with water and filter through Whatmann paper no.1.once washed leaves were traced on graph paper to determine leaf area in $\mathrm{m}^{2}$. Dust fall was calculated ingms $/ \mathrm{m}^{2}$ by method given by (Table 1$)^{6,7}$ 


\section{Results and discussion}

The results of foliar dust collected on Ficus hispida L. in dry season are represented in Table 2.

Table 2 Dust fall on the leaves of Ficus hispida L. in gm. $/ \mathrm{m}^{2}$ at sites during the study.

\begin{tabular}{llllllll}
\hline S. no & Jan & Feb & Mar & Apr & May & Nov & Dec \\
\hline 1 & 60 & 58.125 & 20.001 & 7.976 & 62.73 & 7.982 & 2.83 \\
2 & 75 & 75.154 & 6.538 & 8.85 & 79.28 & 22.44 & 1.54 \\
3 & 35 & 31.01 & 38.696 & 19.68 & 41.22 & 19.68 & 3 \\
4 & 100 & 154.89 & 29.47 & 12.5 & 142.13 & 86.4 & 3.33 \\
5 & 100 & 96.95 & 8 & 22.44 & 88.33 & 53.94 & 2.11 \\
6 & 100 & 121.16 & 7.386 & 5.727 & 86.89 & 8.86 & 1.05 \\
7 & 90 & 109.81 & 63.61 & 85.98 & 94.24 & 63.2 & 1 \\
8 & 27 & 26.06 & 5.88 & 15.538 & 30.21 & 99.1 & 3.06 \\
9 & 180 & 167.77 & 17.96 & 68.36 & 150.29 & 72.28 & 2.99 \\
10 & 150 & 145.36 & 29.784 & 34.29 & 87.88 & 69.11 & 1.53 \\
\hline
\end{tabular}

Anand nagar: This site showed maximum dust fall in month of May $62.73 \mathrm{gms} / \mathrm{m}^{2}$ and drop down in December $2.83 \mathrm{gms} / \mathrm{m}^{2}$ (Figure 1).

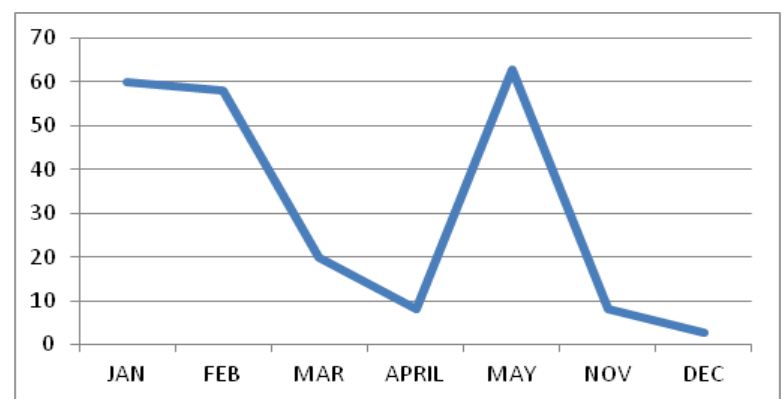

Figure I Seasonal Variation in Dustfall using Ficus hispida L. in $\mathrm{g} / \mathrm{m}^{2}$ at Site I.

Revas road: This site is having heavy traffic and showed maximum dust $79.2 \mathrm{gms} / \mathrm{m}^{2}$ in month of May and minimum $1.54 \mathrm{gms} / \mathrm{m}^{2}$ in December (Figure 2).

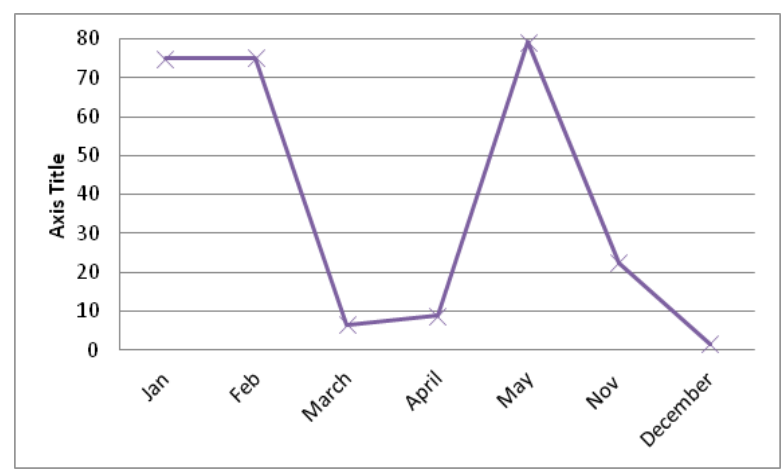

Figure 2 Seasonal Variation in Dustfall using Ficus hispida L. in $\mathrm{g} / \mathrm{m}^{2}$ at Site 2.

Rautwadi road: Maximum dust fall in month of May is $41.2 \mathrm{gms}$ / $\mathrm{m}^{2}$ and minimum $3 \mathrm{gms} / \mathrm{m}^{2}$ in month of December (Figure 3).

Versoli road: Maximum dust fall in month of Feb is $154.89 \mathrm{gms} /$ $\mathrm{m}^{2}$ and minimum $3.33 \mathrm{gms} / \mathrm{m}^{2}$ in month of December (Figure 4).

Revdandabypassroad:MaximumdustfallinmonthofFebis $96.95 \mathrm{gms} /$ $\mathrm{m}^{2}$ and minimum $2.11 \mathrm{gms} / \mathrm{m}^{2}$ in month of December (Figure 5).

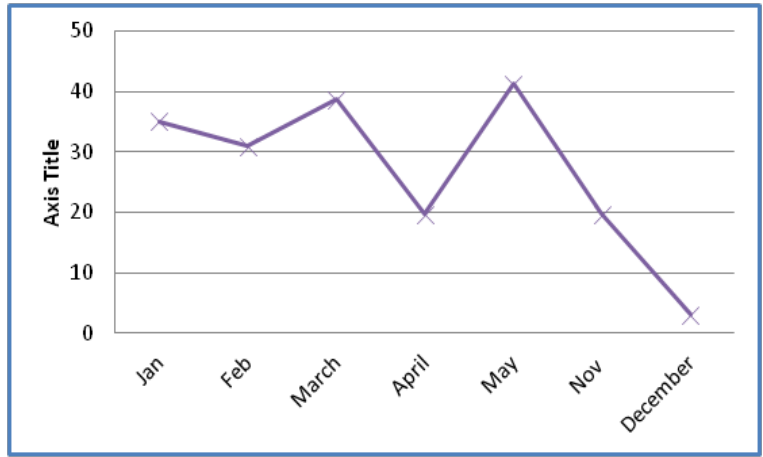

Figure 3 Seasonal Variation in Dustfall using Ficus hispida L. in $\mathrm{g} / \mathrm{m}^{2}$ at Site 3.

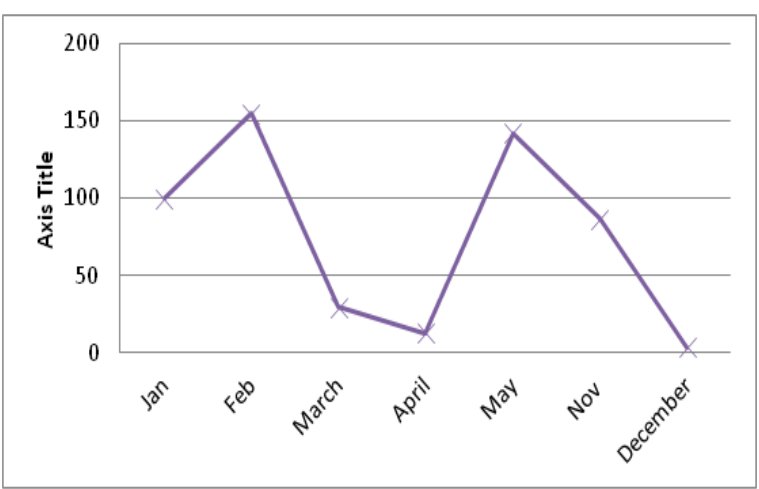

Figure 4 Seasonal Variation in Dustfall using Ficus hispida L. in $\mathrm{g} / \mathrm{m}^{2}$ at Site 4.

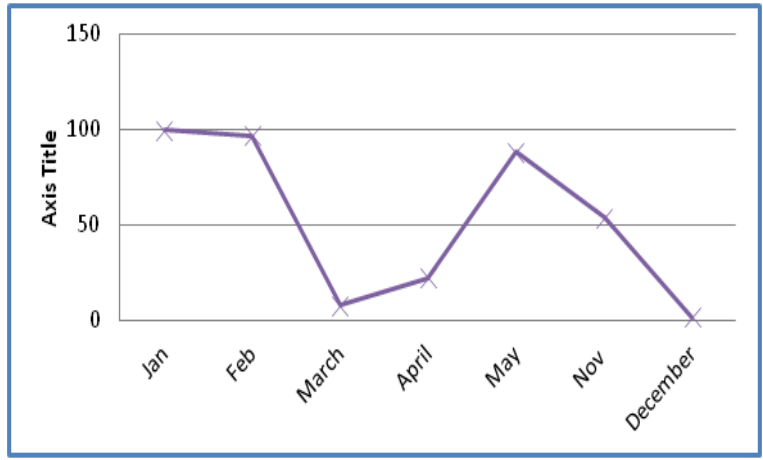

Figure 5 Seasonal Variation in Dustfall using Ficus hispida L. in $\mathrm{g} / \mathrm{m}^{2}$ at Site 5.

Gondhalpada road: Maximum dust fall in month of Feb is $121.16 \mathrm{gms} /$ $\mathrm{m}^{2}$ and minimum $1.05 \mathrm{gms} / \mathrm{m}^{2}$ in month of December (Figure 6).

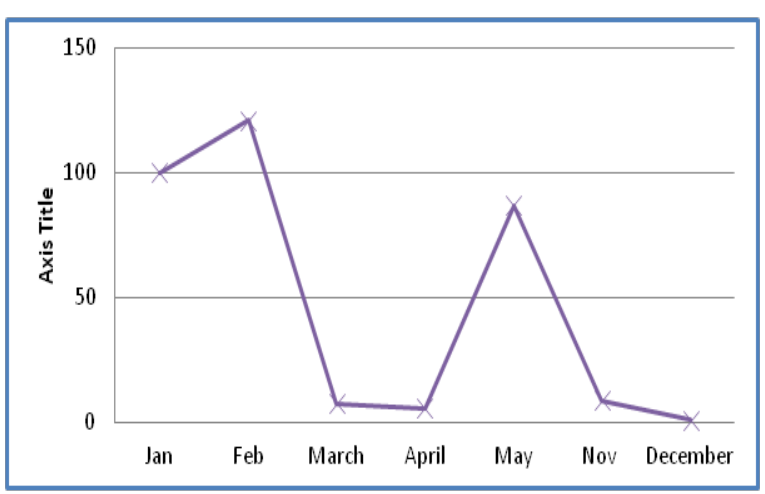

Figure 6 Seasonal Variation in Dustfall using Ficus hispida L. in $\mathrm{g} / \mathrm{m}^{2}$ at Site 6. 
Pimpalbhat road: Maximum dust fall in month of Feb is $109.81 \mathrm{gms} /$ $\mathrm{m}^{2}$ and minimum $1 \mathrm{gms} / \mathrm{m}^{2}$ in month of December (Figure 7).

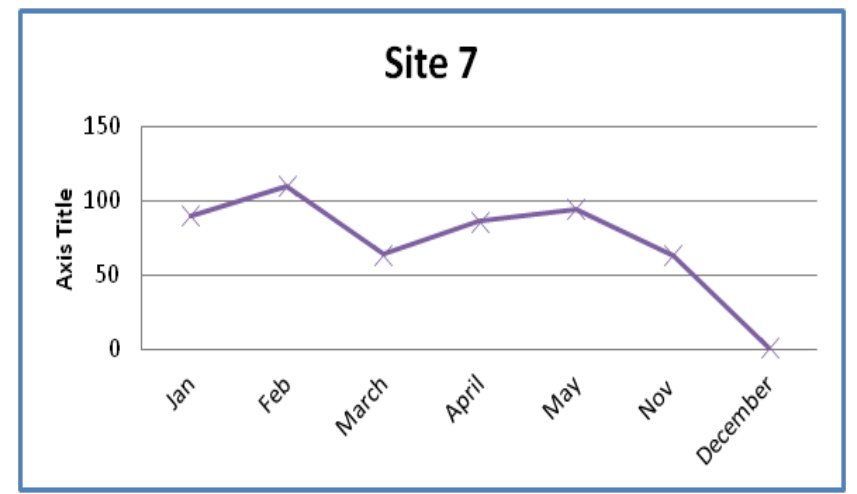

Figure 7 Seasonal Variation in Dustfall using Ficus hispida L. in $\mathrm{g} / \mathrm{m}^{2}$ at Site 7.

Khandala road: Maximum dust fall in month of Feb is $99.10 \mathrm{gms} /$ $\mathrm{m}^{2}$ and minimum $3.0 \mathrm{gms} / \mathrm{m}^{2}$ in month of December (Figure 8).

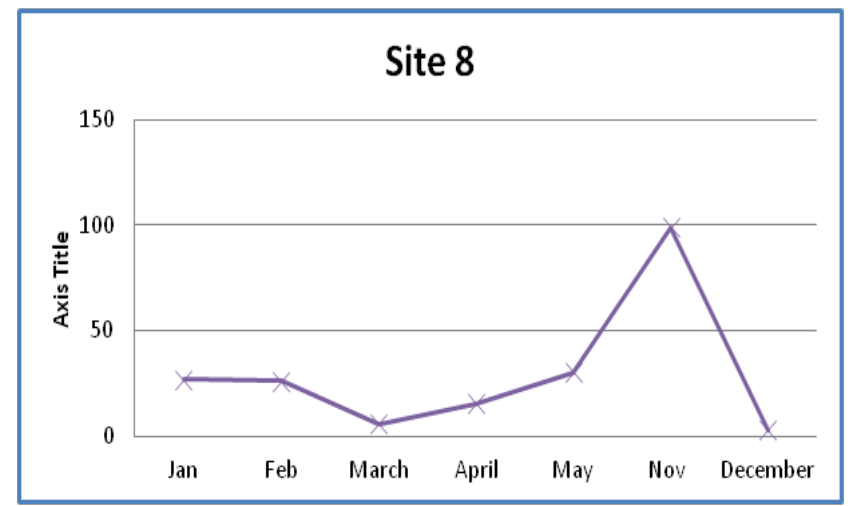

Figure 8 Seasonal Variation in Dustfall using Ficus hispida L. in $\mathrm{g} / \mathrm{m}^{2}$ at Site 8.

Church,bypass road: Maximum dustfall inmonth ofFeb is $167.77 \mathrm{gms} /$ $\mathrm{m}^{2}$ and minimum $2.99 \mathrm{gms} / \mathrm{m}^{2}$ in month of December (Figure 9).

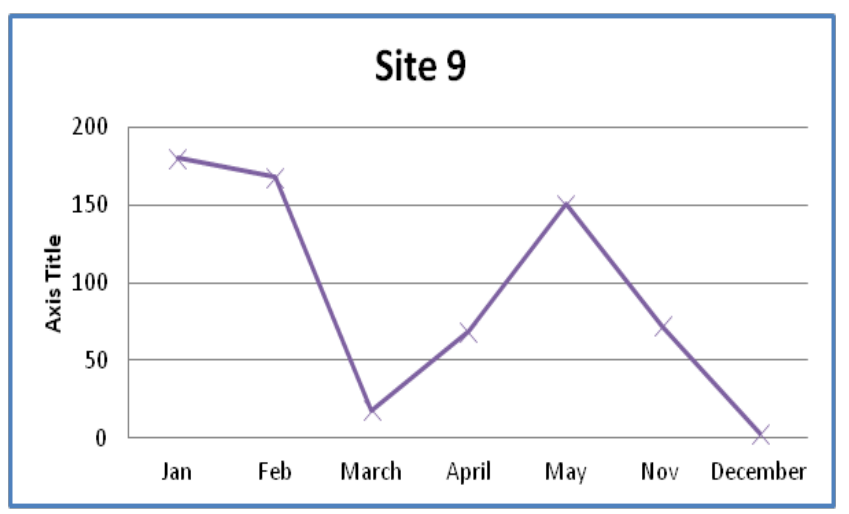

Figure 9 Seasonal Variation in Dustfall using Ficus hispida L. in $\mathrm{g} / \mathrm{m}^{2}$ at Site 9.

Karle khind road: Maximum dust fall in month of Feb is $145.36 \mathrm{gms} /$ $\mathrm{m}^{2}$ and minimum $1.53 \mathrm{gms} / \mathrm{m}^{2}$ in month of December (Figure 10).

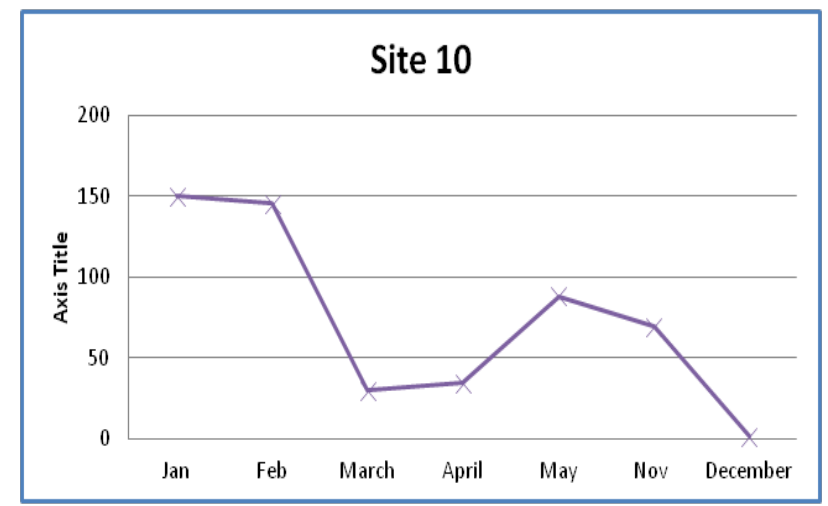

Figure 10 Seasonal Variation in Dustfall using Ficus hispida L. in $\mathrm{g} / \mathrm{m}^{2}$ at Site 10 .

\section{Conclusion}

Ficus hispida recorded maximum dust fall at site 9 in the month of Feb with the value being $167.77 \mathrm{gms} / \mathrm{m}^{2}$. December had the least dust deposition compared to all other months at all study sites. High dust deposition is in month of May, similarly in February. The plants growing near church Bypass Road and Versoli Road showed constantly high values of dust deposition. This is largely due to the location of sites being is an area with high vehicular density. Seasonal variations on dust depostions and the relation between pollution was established by. ${ }^{8-10}$

Ficus

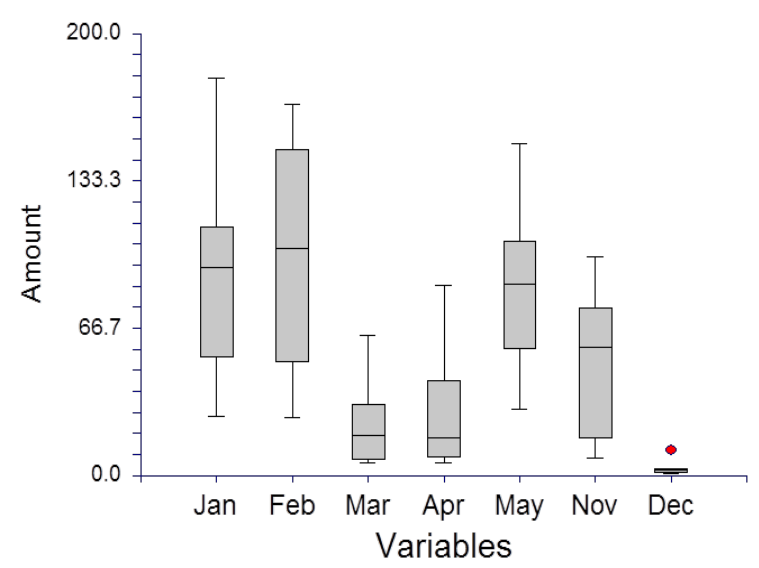

Figure II Box and whisker plots showing dust fall on Ficus hispida at different sites throughout study period.

The plant species has exceptionally rough surface with large leaves, which proves as effective dust capturer.

Using plants as monitors of dust has advantage over highly expensive and sophisticated instruments as they easily available have low maintenance can be cost effective substituent can be placed at specific sites and also do not risk pilferage (Figure 11). 


\section{Acknowledgements}

None.

\section{Conflict of interest}

The authors declare that there is no conflict of interest regarding the publication of this article.

\section{References}

1. Yunus M, Ahmad KJ. Effect of air pollution on some plants. Proc Internat symp Environ. Agents and their Biol Effects. Hyderabad; 1978.

2. Central Pollution Control Board (CPCB). Phytoremediation of particulate matter from ambient environment through dust capturing plant species, a Report under Central Pollution Control Board, Ministry of Environment and Forests, Delhi; 2007.

3. Smith WH. Air pollution and forests interaction between air contaminants and forest ecosystem, 109. Springer Verlanrg New York, Inc; 1981.

4. Prajapati SK. Ecological effect of airborne particulate matter on plants. Environ Skeptics Critics. 2012;1(1):12-22.
5. Saha DC, Padhy PK. Effects of Stone crushing industry on Shorea robusta and Madhuca indica foliage in Lalpahari forest. Atmospheric Pollution Research. 2011;2(4):463-476.

6. Joshi NC. Experiments in Phytomonitoring of Urban Atmosphere. Ph.D. Thesis, University of Mumbai, Maharashtra, India; 1990.

7. Joshi N, Bist B, Mule P, et al. Importance of Common Roadside Plants as Dust Collectors in Tarapur Industrial area. International Research Journal of Science and Engineering. 2014;2(2):31-36.

8. Prajapati SK, Tripathi BD. Seasonal variation of leaf dust accumulation and pigment content in plant species exposed to urban particulates pollution. J Environ Qual. 2008;37:865-870.

9. Joshi NC, Karmarkar SM, Chaphekar SB. Active Phytomonitoring of Urban Ecosystem of Bombay. The changing landscape of plant sciences. 1997;260-282.

10. Joshi N, Joshi A. Dust monitoring potentials of ruderal vegetation of Mumbai. Jr. of Industrial Pollution Control. 2013;29(2):269-274. 